\title{
Online Supervised Exams: Entering the 4th Year at UNE
}

\author{
Jennifer Lawrence and Kylie Day \\ University of New England
}

\begin{abstract}
The University of New England initially embarked on a trial of online supervised exams in early 2017. In the several years since this pilot has expanded considerably, with over half of unit exams offered online by the end of 2019 and almost a quarter of students opting-in. As the global COVID19 crisis emerged the institution transitioned suddenly to a fully online exam period, with the first fully online exam period conducted in June 2020. Given COVID19 has caused many institutions to consider a similar shift the UNE exams team present an account of this project and advice for other institutions on this transition.
\end{abstract}

Keywords: Online Exams, ProctorU, Transforming Assessment, Whole-of-Institution Digital Transformation

\section{Online Exams at UNE}

\section{The UNE Context}

UNE was established primarily as a distance education provider, which has shaped its student cohort since its establishment as an outlier amongst Australia's universities. UNE currently has approximately 22,000 students, the overwhelming majority of which are domestic students (>95\%) studying coursework programs (>95\%) online (>85\%), with over half of these students aged over thirty (Department of Education, 2019). Prior to engaging with online exams UNE coordinated a thrice-annual logistical process to deliver hard copy exam papers to approximately 400 physical examination centres around the world (the majority in regional Australia), at which students sat their exams before the papers were securely posted back to the Armidale campus for marking. This process had been made robust through many years of fine-tuning by the expert centralised examinations team, but was nonetheless vulnerable to regular disruption from natural disasters and world political events. In addition, the rigid scheduling required to administer paper exams securely was becoming incompatible with the expectations for flexibility of UNE's mature online cohort.

\section{The Implementation Project}

In early 2017 a pilot project was launched to deliver online supervised exams for UNE students. After an evaluation process, ProctorU was selected as the supervision platform, with UNE's existing Moodle LMS hosting the exams themselves via the 'quiz' tool. The first online exams were conducted in Trimester 22017 in select units, with students offered an opt-in process and a "Try It Out" exam to test their equipment. After the success of these first exams, additional units incorporated the online option each Trimester (Figure 1), and the proportion of student uptake of the online option increased as students became more aware and confident with online exams (Figure 2).

In mid-March of 2020, in response to the global COVID19 crisis impacting many exam centres, UNE cancelled paper-based exams for Trimester 1, effectively converting the institution to entirely online exams overnight. The exam period was scheduled for early June, giving the institution a little over 10 weeks to prepare. During this period some units converted to alternative forms of assessment, some created online versions of previously paper exams, but many were able to continue with already established online exam practices. This sudden 'emergency' conversion was seen as the final stage of our pilot - a full scale roll out, paving the way for incorporating online exams as the business-as-usual approach.

\section{Tracking the impacts}

\section{Uptake over time}

Typically, a Trimester 1 exam period for UNE involves approximately 16,000 exam sittings by 10,000 students across 350 units of study (with many students undertaking several units with an exam). Prior to COVID19 just 
over half of UNE's units with exams were offering those exams online (Figure 1). Note that there are typically fewer unit offerings during Trimester 3 than during Trimesters 1 and 2.

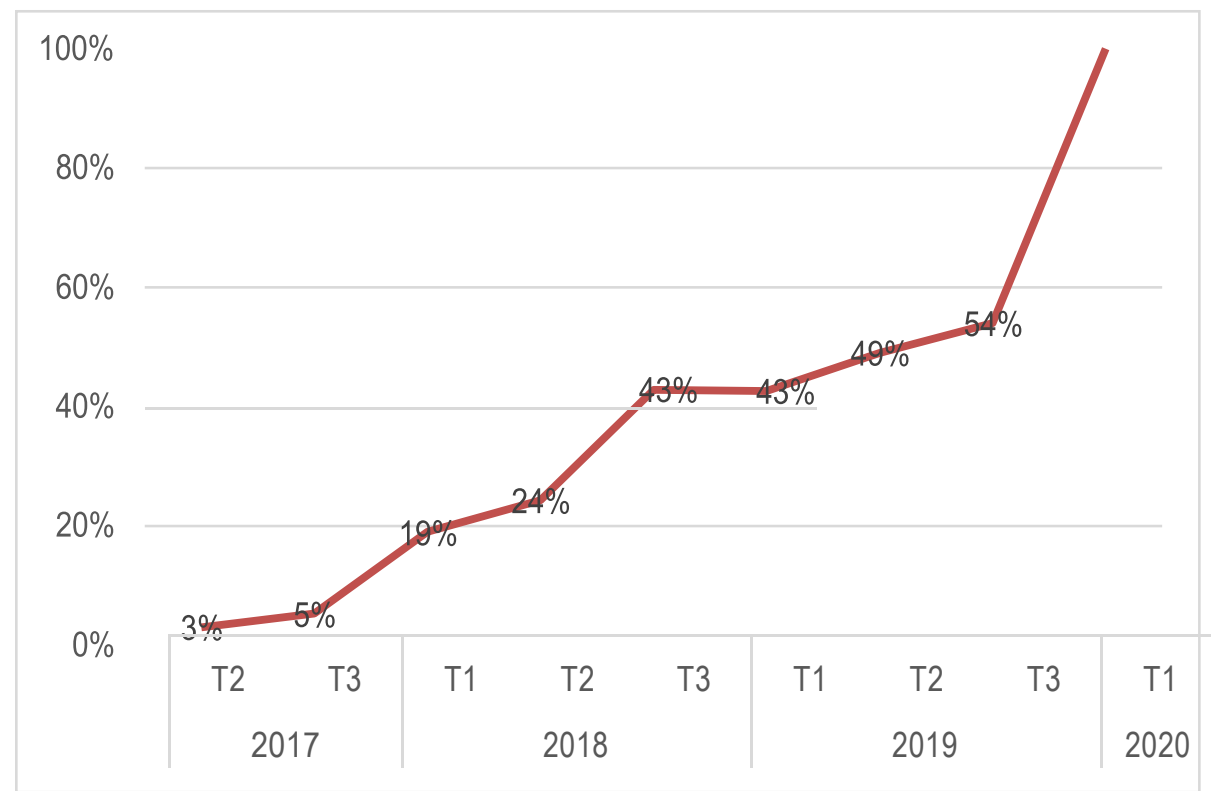

Figure 1: Proportion of unit exams available online

As students awareness of the online exam option increased over time, and the availability of this option in a greater number of units progressed, the proportion of students opting in to online exams increased. Prior to the COVID19 crisis UNE was actively considering whether and how to shift from opt-in to opt-out in order to pursue a full transition from paper-based to online exams. COVID19 changed this conversation, however there was still a small proportion of students who were unable to access online exams either for reasons of disability or medical conditions, access to technology, or concerns related to privacy. These students were given access to alternative forms of assessment rather than an exam, and subsequently some of these units have shifted to the alternative assessment as their standard assessment task, moving away from an exam entirely.

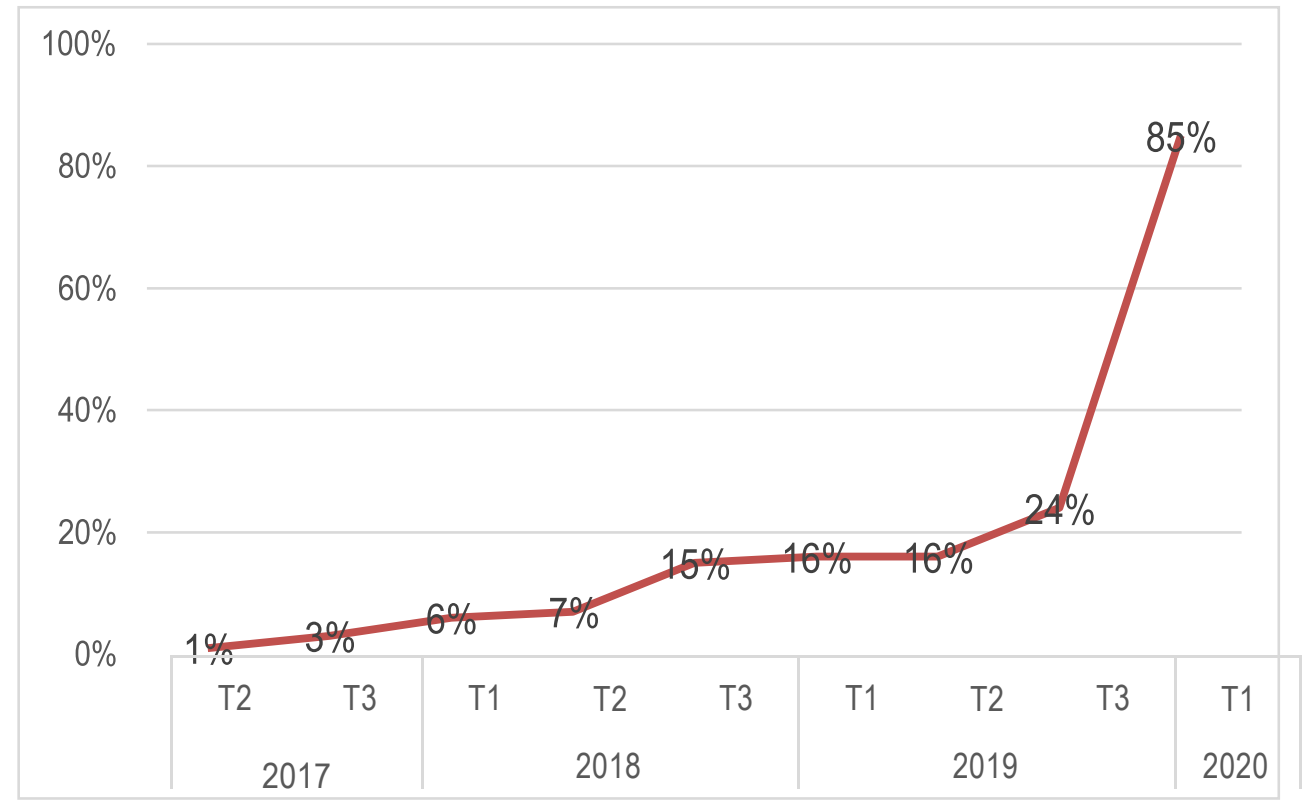

Figure 2: Proportion of exam sittings held online 


\section{Benefits and challenges}

\section{Students}

Over the first several years of this project student reactions to online exams were overwhelmingly positive, likely reflecting their ability to choose this option. Following the shift to a fully online exam period as a result of COVID19 student reactions were much more polarised, likely reflecting the sudden change and lack of choice. Both concerns and excitement were expressed, centred around several broad issues.

\section{Exam anxiety}

An exam is often a focal point for student anxiety - exams are often high stakes and experienced as a stressful and highly ritualised event. Online exams makes dramatic changes to the processes and experiences surrounding this event, and can combine technology anxiety with exam anxiety. The intention of UNE's "Try It Out" exam is to decouple these conflating tensions and ensure students enter their exam knowing what to expect, with the result that students who undertake the Try It Out exam experience a substantially lower proportion of technical issues and other disruptions during their exams than those who have not, and report a much more comfortable exam experience.

\section{Flexibility}

The logistics of paper-based exams require rigidity of time, place, and technology. For example, if a student had an exam commencing at 9am that coincided with their child's first day of school there was little room for flexibility to allow the student to take their exam at a different time. If a student was unwell they were offered a deferred exam during the following exam period, some 3-4 months later. However, the logistical realities of providing several hundred students with exam papers and then collecting them securely do not apply to online exams, allowing a degree of flexibility not otherwise possible. Students are able to select their preferred start time within a 24 hour availability window, removing the need to apply for special consideration. If a student missed their exam for a legitimate reason it could be rescheduled a day or two later. Of particular note are the benefits cited by students with medical conditions or disabilities requiring adjustments. In a paper-based exam setting these students are routinely provided with particular conditions to suit their needs (e.g., ergonomic furniture, specific lighting or paper, assistance technologies, a space free of allergens), however with online exams many of these adjustments are no longer 'special circumstances', rather the student is able to use their own space (with their own furniture/lighting/etc) and is freed from the need to travel to the exam centre.

\section{Privacy}

Prior to the sudden shift to universal online exams UNE had seen very few serious concerns raised by students related to privacy in online exams. Following significant media attention nationwide on this issue UNE received considerable contact from students with queries or concerns. The delicate balance between competing risks (student concerns regarding privacy, and the need for integrity in assessment processes) is one many institutions, including UNE, are still grappling with.

\section{Staff}

Over the course of this project staff at UNE raised a range of issues as sources of excitement or concern.

\section{Marking Workflow}

Due to the time taken for exam papers to return from around the world marking paper-based exams could be a drawn-out process. Online exams allowed teaching staff to view student responses immediately after the completion of the exam, and all at once rather than returning over a period of several weeks.

\section{Alternative Assessment}

In making a sudden shift from opt-in online exams, in which students had a choice between online or paperbased formats, to universal online exams in which the only exams available were online, many staff were caught by surprise by the need to create alternative assessments for the minority of students unable to access online exams.

\section{Academic Integrity}

Concerns are often raised regarding academic integrity assurance within online exams, especially relating to differing start times for individual students. Strategies such as randomised question pools, and application based questions rather than knowledge based questions have previously been considered good exam practice 
regardless of format - online exams makes them essential. In addition, online exams removes ambiguity from investigation processes. Previously accusations of misconduct within a paper-based exam setting might be determined on the basis of the invigilators word against the students. With video, audio, and screen recordings available investigations are resolved more quickly and objectively.

\section{Institutional}

Assessment Design

As a result of discussions related to online exams, the exams team noticed staff across the university became more conscious of their assessment design. Some moved away from exams entirely to other forms of assessment, others experimented actively with the logistical differences to create exams for learning instead of exams of learning.

\section{Organisational Resilience}

The ability to span both exam formats leads to a more resilient exam process. In the years prior to COVID19 many international events (e.g., tsunamis, bushfires, earthquakes, flooding, political or terrorist events) considerably disrupted UNE's exam period for particular groups of students. However, as the paper-based processes were managed entirely by a central team this was largely hidden from the wider institution - online exams brings other teams of staff closer to the management of exams processes, including processes for exceptions and disruptions. Because UNE had embarked on this journey long prior to COVID19, the shift to universal online exams in response to COVID19 was much easier than the authors have witnessed at other institutions, however this was not without challenges. Ultimately, the ability to run either format at scale will allow UNE to better respond to broadscale disruptions in future.

\section{Key learnings from this implementation}

During the early stages of the COVID19 crisis the authors were approached by colleagues at many other universities for advice on online exams, as UNE's pilot was well known. For the benefit of other institutions contemplating implementation of online exams, our key learnings from the past several years, and our recommendations for others considering such a shift, are as follows.

\section{Change and Communications, not just Technology}

At the broad level, we recommend that the introduction of online exams at an institution be seen as a change and communications project, not just a technology implementation project. Online exams can represent a significant transformation of assessment design and experience, creating the need to revisit policies and business processes and communicate those changes with both staff and students. Simply replicating a paper exam on a webpage will realise few of the potential benefits of online exams.

\section{Trigger conversations about assessment}

As is the case with many educational technologies, online exams is a useful trigger for discussions about assessment design. These conversations should be encouraged, with teaching and support staff invited to revisit their choices of assessment mode and consider broader options as suits their educational context. Educationally, an exam is selected as the form of assessment when identity verification and security from collaboration are required - if that is not the case, then another format of assessment is more appropriate. With this perspective, a situation in which a unit coordinator decides to shift away from an exam entirely rather than pursue online exams should be seen as an assessment success story, rather than a failure of the online exams process.

\section{Practical Tips}

In addition to these broad conceptual recommendations, some practical and operational approaches can considerably smooth the online exams experience.

- A 'Try It Out' exam, in which students can both test their technology and become comfortable with the

- online exams interface, is critical for both student confidence and a smooth support process.

- Using a consistent whole-of-institution approach for alternative assessment needs leads to less confusion. 


\section{Conclusion}

The University of New England's experience with online exams is, to the knowledge of the authors, unique amongst Australian universities. However, with many other institutions rapidly shifting towards online exams as a result of COVID19 restrictions this is unlikely to be true for long. As our students connect and converse on this topic, so should we, and share our experiences across institutions in pursuit of collective best practice.

\section{References}

Department of Education. (2019). Higher Education Statistics. Retrieved from Department of Education: https://www.education.gov.au/higher-education-statistics

O'Reilly, G., \& Creagh, J. (2016). A Categorization of Online Proctoring. Global Learn, (pp. 542-552). Limerick. Retrieved June 2020, from https://www.learntechlib.org/p/172801/

Lawrence, J. \& Day, K. (2020). Online Supervised Exams: Entering the 4th Year at UNE. In S. Gregory, S. Warburton, \& M. Parkes (Eds.), ASCILITE's First Virtual Conference. Proceedings ASCILITE 2020 in Armidale (pp. 312-316). https://doi.org/10.14742/ascilite2020.0136

Note: All published papers are refereed, having undergone a double-blind peer-review process.

The author(s) assign a Creative Commons by attribution licence enabling others to distribute, remix, tweak, and build upon their work, even commercially, as long as credit is given to the author(s) for the original creation.

(C) Lawrence, J. \& Day, K. 2020 